\title{
Agricultura familiar no Vale do Rio Pardo (RS): reflexões sobre o saber-fazer das mulheres
}

\author{
Verenice Zanchi ${ }^{1}$ \\ Mariana Barbosa de Souza²
}

\begin{abstract}
Resumo: Este estudo propõe uma análise das atividades desempenhadas pelas mulheres nas propriedades de agricultura familiar no Vale do Rio Pardo, especialmente as que compõem a Rota Germânica do Rio Pardinho e o Roteiro Caminhos da Imigração. A pesquisa respalda-se nos estudos de gênero, partindo da compreensão de que gênero é uma categoria analítica e carece de uma abordagem qualitativa. Por meio do trabalho empírico que realizamos nas pequenas propriedades, objetivamos entender o contexto das ações desempenhadas pelas agricultoras, compreendendo de maneira profunda suas contribuições, não somente para o contexto doméstico, mas também para a manutenção da propriedade, que, associada à agroecologia, contribui para o desenvolvimento da região em análise. As entrevistas realizadas com as agricultoras têm como ponto central analisar as falas destas mulheres, seus cotidianos, suas relações e seus entendimentos sobre o rural. Destacamos que, diante da presença do turismo rural, o alimento e o artesanato foram ressignificados pelas mulheres e detêm um papel importante na renda familiar, em que pese a forte presença do patriarcalismo e o reforço de estereótipos como o da não valorização do trabalho doméstico, basicamente realizado pelas mulheres. A divisão sexual do trabalho também influi para a perpetuação de estereótipos e de modelos culturais que colocam a mulher em subalternidade em relação ao homem, consequentemente, o saber-fazer das mulheres camponesas é minimizado e até mesmo ignorado. Logo, a pesquisa demonstra as inúmeras contribuições familiares das mulheres agricultoras para o desenvolvimento da região do Vale do Rio Pardo, embasando um entendimento para as práticas diárias e seus saberes.
\end{abstract}

Palavras-chave: Mulheres. Agricultura familiar. Gênero. Desenvolvimento regional.

Abstract: This study proposes an analysis of the activities carried out by women in family farming properties in the Rio Pardo Valley, especially those that make up the Rota Germânica do Rio Pardinho and the Roteiro Caminhos da Imigração. Research is based on gender studies, based on the understanding that gender is an analytical category and lacks a qualitative approach. Through the empirical work that we carry out in small farms, we aim to understand the context of the actions carried out by the farmers, understanding in depth their contributions, not only for the domestic context, but also for the maintenance of the property, which, together with agroecology, contributes to development of the region under analysis. The interviews conducted with women farmers have as a central point to analyze the statements of these women, their daily lives, their relationships and their understandings about the rural. We emphasize that, given the presence of rural tourism, food and handicrafts have been re-signified by women and play an important role in family income, despite the strong presence of patriarchalism and the reinforcement of stereotypes, such as the non-valuation of domestic work, basically performed by women. The sexual division of labor also influences the perpetuation of stereotypes and cultural models that place women in subordination, in relation to men, consequently the know-how of peasant women is minimized and even ignored. Therefore, the research demonstrates the innumerable contributions of women family farmers to the development of the Pardo River Valley region, underpinning an understanding of daily practices and their knowledges.

Keywords: Women. Family farming. Genre. Regional development.

\footnotetext{
${ }^{1}$ Doutoranda em Desenvolvimento Regional pela Universidade de Santa Cruz do Sul - UNISC. hi@gmail.com.

2 Doutoranda em Desenvolvimento Regional pela Universidade de Santa Cruz do Sul - UNISC. marisouza_10@hotmail.com.
} 


\section{Introdução}

Neste estudo, propomos uma análise das atividades desempenhadas pelas mulheres nas propriedades de agricultura familiar no Vale do Rio Pardo, especialmente as que compõem a Rota Germânica do Rio Pardinho e o Roteiro Caminhos da Imigração. Trata-se de uma região colonizada por imigrantes europeus, ao longo do século XIX, na qual a agricultura familiar destaca-se como importante segmento social.

A pesquisa respalda-se nos estudos de gênero, partindo da compreensão de que gênero é uma categoria analítica e carece de uma abordagem qualitativa, devendo ser entendido como intrínseco às relações sociais e atravessado por jogos de poder. $\mathrm{O}$ trabalho empírico realizado nas pequenas propriedades teve como objetivo entender o contexto das ações desempenhadas pelas agricultoras, compreendendo de maneira profunda suas contribuições, não somente para o contexto doméstico, mas também para a manutenção da propriedade, que, associada à agroecologia, contribui para o desenvolvimento da região em análise.

A escrita deste artigo, no que diz respeito à metodologia, foi pautada na abordagem dialética, que aponta para uma concepção crítica do mundo, em que teoria e método encontram-se na dimensão teórica e permitem a interpretação de uma determinada realidade posta. As técnicas utilizadas foram as pesquisas bibliográfica e documental. Realizamos, ainda, seis entrevistas em profundidade, em propriedades no município de Santa Cruz do Sul, as quais tiveram como ponto central analisar as falas das mulheres, seus cotidianos, suas relações e seus entendimentos sobre o rural.

Ademais, é importante considerar que as propriedades se encontram inseridas em roteiros turísticos; portanto, tentamos evidenciar as práticas diárias insertas no dia a dia das agricultoras e como este é afetado, modificado e atravessado por contradições a partir das transformações realizadas no rural. Nas propriedades em estudo, estão presentes, além do turismo rural, diversas atividades agrícolas, como a produção leiteira, a produção agropecuária, entre outras.

Destacamos que, diante da presença do turismo rural, o alimento e o artesanato foram ressignificados por essas mulheres e detêm um papel importante na renda familiar, 
em que pese a forte presença do patriarcalismo e o reforço de estereótipos, como o da não valorização do trabalho doméstico, basicamente realizado pelas mulheres. A negação e até mesmo a ignorância da importância deste trabalho fazem com que o papel da mulher na manutenção da segurança alimentar, da sustentabilidade e do desenvolvimento regional seja invisibilizado.

A divisão sexual do trabalho também influi na perpetuação de estereótipos e de modelos culturais que colocam a mulher em subalternidade em relação ao homem, consequentemente, o saber-fazer das mulheres camponesas é minimizado e até mesmo ignorado. Logo, a pesquisa demonstra as inúmeras contribuições familiares das mulheres agricultoras para o desenvolvimento da região do Vale do Rio Pardo, embasando um entendimento para as práticas diárias e seus saberes.

Além da introdução e das considerações finais, o artigo está dividido em mais três seções. Na segunda seção, é realizada uma discussão sobre o desenvolvimento regional, a agricultura familiar e os esforços dessas famílias para permanecerem em suas propriedades, assim como uma breve caracterização da região - o Vale do Rio Pardo. Na terceira seção, as questões de gênero são analisadas sob o prisma da mulher agricultora familiar. Na quarta seção, são analisados os dados coletados e o material das entrevistas, que revelam a representatividade do trabalho das mulheres na composição da renda da propriedade, bem como o sentimento de união familiar, sentido após o desenvolvimento da atividade turística nas propriedades.

\section{Desenvolvimento regional a partir da agricultura familiar}

Inicialmente, cabe destacar que entendemos o desenvolvimento regional a partir da concepção de desenvolvimento de Sen (2000, p. 10), que define que "[...] o desenvolvimento consiste na eliminação de privações de liberdade que limitam as escolhas e as oportunidades das pessoas de exercer ponderadamente sua condição de agente". Nessa perspectiva, os atores estão ativamente envolvidos na configuração de seu próprio destino e participam de processos democráticos e de debates políticos, na condição de "agentes", decidindo onde as 
verbas serão alocadas, participação essa que faz parte dessa liberdade defendida por Sen (2000).

No Brasil, a partir dos anos 1970, o desenvolvimento regional passa a ser visto de dentro para fora, ou seja, como endógeno. Nas palavras de Benko (1999, p. 288), trata-se de “[...] uma estratégia de diversificação e de enriquecimento das atividades sobre um dado território com base na mobilização de seus recursos (naturais, humanos e econômicos) e de suas energias". Para Boisier (1996), o desenvolvimento de um território organizado depende da existência, da interação e da articulação de seis elementos - atores, instituições, cultura, procedimentos, recursos e entorno, dos quais depende o sucesso ou o fracasso da região.

Nesse sentido, Brandão (2004, p. 70) afirma que o desenvolvimento é um processo resultante de variadas e complexas interações sociais e que

[...] esse processo deve promover a ativação de recursos materiais e simbólicos e a mobilização de sujeitos sociais e políticos buscando ampliar o campo de ação da coletividade, aumentando a sua autodeterminação e liberdade de decisão. Neste sentido, o verdadeiro desenvolvimento exige envolvimento e legitimação de ações disruptivas e emancipatórias, envolvendo, portanto, tensão, eleição de alternativas e construção de trajetórias históricas, com horizontes temporais de curto, médio e longo prazos.

No contexto do desenvolvimento regional, o turismo rural tem contribuído como alternativa de enfrentamento às adversidades econômicas, principalmente na agricultura familiar ${ }^{3}$. Cabe destacar que o desenvolvimento da região do Vale do Rio Pardo está alicerçado na agricultura familiar desenvolvida em pequenas propriedades, característica herdada da época da colonização e das características geográficas locais.

Contudo, essas famílias vêm enfrentando dificuldades, decorrentes inicialmente do processo de mecanização da produção, mais precisamente da Política de Crédito Agrícola brasileira das décadas de 1970 e 1980, a qual estava direcionada a atender médios e grandes

\footnotetext{
${ }^{3}$ Agricultura Familiar referida, diz respeito aos sujeitos contemplados pela Lei 11.326/06 (BRASIO, 2006), a qual reconhece a agricultura familiar como segmento produtivo e representa um novo marco para as políticas públicas destinadas ao desenvolvimento rural, desde a fase de elaboração até a implementação, execução e gestão de recursos. Estabelece como parâmetro o agricultor ou agricultora familiar que não tenha propriedade maior do que quatro módulos fiscais, que utilize predominantemente mão de obra da própria família nas atividades econômicas do seu empreendimento, que tenha renda familiar predominantemente originada de atividades econômicas vinculadas ao próprio estabelecimento ou empreendimento, entre outros. Também acrescentamos os silvicultores, aquicultores, extrativistas artesanais, pescadores artesanais, povos indígenas, integrantes de comunidades remanescentes de quilombos rurais e demais povos e comunidades tradicionais. Todos incluídos pela Lei no 12.512 (BRASIL, 2011).
} 
produtores. Conforme Schneider (1999) e Silva e Campanhola (2000), os impactos negativos dessas políticas ainda podem ser encontrados em muitos municípios do Estado do Rio Grande do Sul.

Para mitigar tais impactos, na década de 1990, foi promovido um debate sobre o turismo entre governo, iniciativa privada, academia e sociedade, do qual resultaram iniciativas públicas para o setor. O Plano Nacional de Municipalização do Turismo - PNMT - é uma dessas iniciativas, que tem como objetivo melhorar o produto turístico em âmbito municipal (BENI, 2006).

Assim, a partir da década de 1990, o turismo foi introduzido na região do Vale do Rio Pardo com o intuito de contribuir com o desenvolvimento da região, ou seja, ajudar a reduzir o desemprego, o êxodo e o despovoamento das áreas rurais, as quais têm o cultivo do tabaco como produção-base. A concentração nessa produção acaba gerando uma grande dependência regional do setor fumageiro.

O Vale do Rio Pardo destaca-se com $19,92 \%$ de todo o fumo em folha produzido no Brasil (no período de 2008 a 2012). [...] No caso do Vale do Rio Pardo, pode-se destacar inicialmente a dependência econômica gerada por este sistema, na medida em que a economia dos municípios se encontra amplamente alicerçada sobre a produção do tabaco. Prova disso é que a participação do tabaco no Valor Bruto da Produção agrícola dos municípios do Vale do Rio Pardo é, em média, de 61,5\% (IGBE, 2010), o que caracteriza o tabaco como uma monocultura na região (GOMES, 2014, p. 17).

Os dados apontados por Gomes (2014) evidenciam a forte ligação econômica da região com esse segmento, tanto da indústria de beneficiamento da matéria-prima quanto da indústria cigarreira. Cabe destacar que existe na região certo consenso, fomentado pela indústria, pelos políticos e pela mídia, de que a atividade econômica mais rentável para a agricultura familiar é a produção do tabaco.

Para além desse senso comum, o turismo rural se apresenta como uma oportunidade interessante de diversificação de renda nas propriedades familiares. No contexto de desenvolvimento regional, a atividade turística gera a circulação de divisas entre uma região e outra (BENI, 2002). Entretanto, essa atividade surge para os agricultores familiares não só como uma possibilidade de trabalho e renda, mas como uma oportunidade de viver melhor. 
Assim, a diversificação de atividades, nas pequenas propriedades rurais, tem contribuído com o aumento e a redistribuição da renda entre os membros do núcleo familiar, inclusive com o meio ambiente, por meio do uso sustentável da terra.

Cabe destacar que os agricultores familiares que têm diversificado econômica e produtivamente suas propriedades por meio da atividade turística optaram por reduzir ou mesmo eliminar o cultivo do tabaco, com o objetivo de viver melhor. Sen (2000) considera que a diversificação contribui com a redução da dependência das famílias com uma única cultura e tem grandes chances de melhorar a renda familiar. Para Almeida e Riedl (1998), o turismo rural, enquanto atividade de diversificação da propriedade, impõe-se contra os alicerces tradicionais da agricultura, que subjugam a produção, que está exposta ao risco, às incertezas e à exaustão.

Segundo Cristóvão (2002, p. 81), o desenvolvimento rural está ligado à diversificação e ao "[...] reconhecimento de que o espaço rural é bem mais do que um simples fornecedor de matérias-primas", mas, no fundo, um espaço multifuncional. Perceber o espaço rural como um lugar multifuncional implica, ainda, valorizar seus recursos e reconhecer seu potencial endógeno (CRISTÓVÃO, 2002). Blos (2000) aponta para desenvolvimento do turismo rural como alternativa para gerar melhoria da qualidade de vida, produção econômica e serviços.

\section{Refletindo sobre gênero a partir das agricultoras familiares}

Primordialmente, ressaltamos que este artigo não tem a intenção de revisar detalhadamente conceitos de gênero que já são amplamente debatidos no ambiente acadêmico, nem mesmo discutir estes conceitos em sua essência. Ao contrário, buscamos demonstrar quais desses conceitos foram apropriados para melhor compreensão da abordagem de gênero nos estudos rurais, entendendo que a diversidade é um elemento importante para a compreensão da construção do espaço rural não normativo, além de elemento fundamental para o entendimento das particularidades que lhe são intrínsecos. Dessa forma, o trabalho é carregado de um olhar crítico para aquilo que é socialmente construído como natural para a mulher e para o lugar que ela, em tese, deveria ocupar na 
sociedade. Indo além, considera-se ainda de que forma esta construção social influencia na produção do espaço rural, tendo em vista que ela se dá diante de relações sociais que se reproduzem e são contingenciadas, mas também tensionadas e reconfiguradas a partir de diferentes realidades.

No que se refere às mulheres agricultoras, tanto o trabalho quanto à sua própria condição foram, historicamente, marginalizados, isso porque, segundo Perrot (2005, p. 11), “[...] as mulheres agricultoras ou de artesãos, cujo papel econômico era considerável, não são recenseadas, e seu trabalho, confundido com as tarefas domésticas e auxiliares. Tornase, assim, invisível". Isso aponta para outra questão importante: as relações de gênero são construídas social, cultural e historicamente, e mais, segundo Scott (1995, p. 26): “[...] gênero deve ser visto como elemento constitutivo das relações sociais, baseadas em diferenças percebidas entre os sexos, e como sendo um modo básico de significar relações de poder".

Logo, tanto por meio de literatura, como é o caso de Hernández (2009), quanto das práticas sociais observadas nas propriedades visitadas, o que percebemos foi uma forte reprodução de estereótipos que designam ao homem os afazeres da produção, e à mulher as questões que tocam à vida doméstica, ao lar, dando maior importância ao trabalho realizado pelos homens. Nesse sentido, segundo Souza, Vergutz e Costa (2017, p. 113),

[...] as percepções das famílias e das jovens refletem o imaginário sócio-cultural construído historicamente pela humanidade sobre as mulheres. Ou seja, a mulher compreendida apenas no aspecto biológico e fisiológico, na perspectiva sexual, com comportamentos predestinados e naturalizados a partir de uma condição moral. E outro aspecto relacionado à desvalorização do trabalho feminino, no contexto da agricultura e da sua sabedoria, é a conotação do trabalho feminino como 'ocupação' ou como complementaridade, menos valorizados socialmente para o mercado e sendo, portanto, caracterizado como ajuda já que o conceito de trabalho socialmente relaciona-se aos aspectos da produção, com geração direta de renda e, dessa forma, os cuidados da vida humana, de pequenos animais, de plantas medicinais, entre outros aparecem pela aparência da ajuda, do apoio.

É necessária uma superação desses estereótipos, especialmente porque, em se tratando das mulheres, a tomada de consciência em relação à discriminação de gênero permite uma alteração na própria imagem e nos próprios sentimentos, tanto os de inferioridade quanto de impotência, permitindo, assim, uma autonomia. "O aumento da 
autoconfiança, a abertura para as mudanças e ação para promovê-las são, assim, inseparáveis" (GOUVEIA; ISMAEL; CAMINO, 2008, p. 83).

\section{0 saber-fazer das mulheres - a oferta de alimentos e artesanato}

Dentre os roteiros de turismo rural identificados na região do Vale do Rio Pardo, esta pesquisa detém-se em dois, a Rota Germânica do Rio Pardinho e o Roteiro Caminhos da Imigração. A Rota Germânica de Rio Pardinho foi lançada em 26 de junho de 1998 e tem como finalidade manter a tradição, por meio da preservação dos hábitos e costumes originais dos colonizadores do século XIX, da arquitetura, da gastronomia e do artesanato. A vida tipicamente colonial, ou seja, a oportunidade de convívio com as famílias, acompanhando o seu dia a dia nas propriedades; as belas paisagens, formadas por um conjunto de rios e vales; os cafés coloniais; as pousadas; os restaurantes e as lojas de artesanato fazem parte do rol de atrativos oferecidos aos turistas.

A Rota Germânica de Rio Pardinho conta com dezessete atrativos, sendo oito no município de Santa Cruz do Sul: Cervejaria Heilige, Barragem Lago Dourado, Mosteiro da Santíssima Trindade, Igreja Imigrante, Cucas Gressler, Salão Waechter, Basteleihaus - Casa de Trab. Manuais - e Restaurante Vale Verde, e nove em Sinimbu: Arte Haus, Igreja Nossa Senhora da Glória, Artesanato Sinimbu, Quiosque, Floricultura Wendland, Gruta Nossa Senhora de Lurdes, Igreja Evangélica de Sinimbu, Agroindústria Panke e RPPN UNISC Reserva Particular do Patrimônio Natural.

A Basteleihaus (casa de trabalhos manuais) e a Artehaus (casa de arte) trabalham com artesanato sustentável, utilizando sementes, palha de milho, latas e outros materiais reciclados para a confecção das peças. Cabe destacar que a família responsável pela Artehaus reduziu o plantio de tabaco após a implementação da atividade turística. A família Pranke, após a instalação da agroindústria na propriedade e posterior entrada no roteiro, parou a produção de tabaco e, atualmente, produz e comercializa os mais diversos tipos de cucas, tortas, bolos e pães. Também a família proprietária da Cucas Gressler, que comercializa cucas e produtos coloniais como schimier, linguiça, tortas, rocamboles, 
bolachas, pão caseiro, entre outros produtos da gastronomia típica alemã, parou a produção de tabaco.

O Roteiro Caminhos da Imigração, inaugurado em 19 de fevereiro de 2000, tem por objetivo manter a tradição, a arquitetura, a gastronomia e o artesanato característicos da colonização alemã do século XIX. Está localizado entre os distritos de Boa Vista e de Linha Santa Cruz, ambos no município de Santa Cruz do Sul. Vinte atrativos compõem o roteiro: Aeroporto Luiz Beck da Silva, Cooperativa Agrícola Linha Santa Cruz, Residência de José Germano Frantz, Casa Comercial e Salão de Bailes Frantz - Associação de Damas, Capril Boa Vista, Casa em Estilo Enxaimel, Cemitério Evangélico de Alto Linha Santa Cruz, Centro Esportivo Recreativo Cultural Chácara Bauermann, Centro Histórico de Boa Vista, Cruz dos Assmann, Escola Estadual Professor Affonso Pedro Rabuske, Família Fritz e Frida, Igreja Evangélica de Confissão Luterana do Brasil de Linha Andrade Neves, Igreja Evangélica de Alto Linha Santa Cruz, local da primeira missa, Mirante de Boa Vista, Paróquia Santos Mártires das Missões de Linha Santa Cruz, Pousada Camponesa, Rua José Germano Frantz, Sítio Sete Águas.

Nesse roteiro, destacam-se a propriedade na qual está estabelecida a Pousada Camponesa e a propriedade chamada de Sítio Sete Águas, pois ambas abandonaram completamente o cultivo do tabaco. Na primeira, todo o cultivo da propriedade está voltado para a produção orgânica. Seus proprietários preservam ainda as fontes naturais de água existentes na propriedade e a mata nativa, a qual serve de sombra para as trilhas espalhadas pela propriedade. A segunda mantém uma horta, na qual os visitantes podem "colher e levar" os produtos. Também são conservadas as nascentes e parte da mata nativa, principalmente nas margens do rio que recorta a propriedade.

Nos dois roteiros, identificamos experiências que relacionam o turismo rural às atividades próprias da agricultura familiar, voltadas para a subsistência e comercialização; preocupadas ambientalmente, portanto, com o que produzem e, também, com os valores culturais passados de geração para geração, os quais estão sendo ressignificados conforme o entendimento desses/as agricultores/as. O turismo rural vem sendo pensado e articulado, seja entre os agricultores familiares, seja entre os poderes públicos e as associações de 
turismo rural, em rotas organizadas, com o objetivo de aproximar as pessoas à realidade da agricultura familiar nas regiões.

Nesse contexto, o alimento e o artesanato vêm exercendo importante papel como atrativos nos roteiros de turismo rural nessa região. As famílias envolvidas na atividade turística, ao ressignificar o alimento e o artesanato, exercem sua capacidade de fazer e de agir. Ressignificar refere-se, aqui, à decisão das famílias de converter o alimento e o artesanato em atrativos nos roteiros de turismo rural, cujo saber-fazer resulta de tradições transmitidas de geração para geração. Assim, para essas famílias participantes dos roteiros, o alimento e o artesanato passam a ser vistos como possibilidade de geração de renda, os quais são atividades desempenhadas, essencialmente, pelas mulheres.

A partir da análise do Quadro 1, que apresenta a composição da renda nas propriedades entrevistadas, fica evidente a relevância do trabalho das mulheres nessas propriedades que adotam o turismo como fonte de renda, pois são elas as responsáveis pelo preparo do alimento, pela confecção do artesanato e pela limpeza e organização dos espaços de hospedagem.

\section{Quadro 1 - Composição da renda na propriedade, por categoria}

\begin{tabular}{|c|c|c|c|c|c|c|}
\hline Roteiro & Propriedade & Alimento & Artesanato & Hospedagem & $\begin{array}{c}\text { Agricultura } \\
\text { e Pecuária }\end{array}$ & $\begin{array}{c}\text { Aposenta- } \\
\text { doria }\end{array}$ \\
\hline \multirow{4}{*}{$\begin{array}{c}\text { Rota } \\
\text { Germânica do } \\
\text { Rio Pardinho }\end{array}$} & Propriedade 1 & $50 \%$ & & & $40 \%$ & $10 \%$ \\
\hline & Propriedade 2 & & $20 \%$ & & & $80 \%$ \\
\hline & Propriedade 3 & $28 \%$ & & & $8 \%$ & $64 \%$ \\
\hline & Propriedade 4 & $100 \%$ & & & & \\
\hline \multirow{2}{*}{$\begin{array}{c}\text { Roteiro } \\
\text { Caminhos da } \\
\text { Imigração }\end{array}$} & Propriedade 5 & $20 \%$ & & $40 \%$ & $40 \%$ & $10 \%$ \\
\hline & Propriedade 6 & $50 \%$ & & $20 \%$ & $20 \%$ & $10 \%$ \\
\hline
\end{tabular}

Fonte: Elaborado pelas autoras (2018).

Na propriedade 1, as mulheres são responsáveis pela elaboração do alimento que é oferecido como produto turístico, ou seja, 50\% da renda, mas também desempenham atividades relacionadas à agricultura, como plantar e colher, conforme a sazonalidade de 
cada cultivo. E, também, são responsáveis pela pecuária, contribuindo, por fim, com a renda auferida pela aposentadoria da matriarca da família.

Toda a renda da propriedade 2 está alicerçada no artesanato e na aposentadoria das duas mulheres que residem na propriedade, pois tanto o marido quanto o pai morreram, uma característica observada nas outras propriedades. Os filhos realizam as demais atividades da propriedade, mas, como não residem na mesma, a renda advinda desse trabalho não foi contabilizada.

Na propriedade 3, a renda advinda do artesanato é inteiramente de responsabilidade da mulher, bem como parte dessa renda é relativa à aposentadoria. Cabe destacar que os $8 \%$ da renda relacionada à terra não provêm do seu cultivo, mas de arrendamento. A propriedade 4 é peculiar, porque 100\% dos rendimentos estão atrelados ao alimento, e é a mulher quem a administra, preparando e vendendo esses alimentos, sendo que a cunhada ajuda na preparação, e o neto, na venda.

As propriedades 5 e 6 têm similitudes tanto entre si, na composição da renda, quanto com a propriedade 1 , com relação ao fato de as mulheres também desempenharem atividades relacionadas à agricultura e à pecuária. A propriedade 5 assemelha-se ainda à propriedade 1 no que tange à renda, que é advinda da aposentadoria da matriarca da família.

Nas entrevistas, constatamos que, em $84 \%$ das propriedades, as mulheres não somente são responsáveis pelo alimento, pelo artesanato e pela hospedagem, mas também pela iniciativa de diversificar as atividades da propriedade, inserindo essa alternativa de renda. Cabe destacar que houve apoio recíproco entre as integrantes de um mesmo roteiro.

Depois do esforço inicial e dos primeiros retornos positivos, a família costuma apoiar e contribuir de alguma forma, quando possível, mas a maior parte do trabalho é realizado pela mulher. Os motivos variam, mas a necessidade de aumentar a renda é fator comum para todos. Para além da renda, o contato com outras pessoas, no caso, os turistas, aparece nas falas e tem um significado imaterial. Quando questionados sobre como avaliam as mudanças que a atividade turística lhes proporciona, são unânimes ao responder que são positivas. 
Ainda com relação às mudanças que a atividade turística tem trazido para a família, a entrevistada 1 afirma que "Através do turismo, da divulgação, apareceram parentes. Se conhece muita cultura diferente". Segundo a entrevistada 2: "Ajudou bastante, a partir que começamos a participar a gente está mais junto. Uniu mais a família. Maior integração". No mesmo sentido, a entrevistada 3 destaca que "O contato com outras pessoas ajudou na desinibição". Para a entrevistada 4, "Conhecer outras pessoas e o envolvimento com pessoas de fora da comunidade" são as principais vantagens. 
A entrevistada 5 infere que

As pessoas gostam muito de vir aqui, a gente pegou um outro tipo de
conhecimento, de atividade que exige tu mostrar os dentes para as pessoas mesmo
às vezes dando uma coisa atravessada. A gente ainda não teve grandes retornos
financeiros porque a gente tem que investir cada vez mais. Tem que investir muito
todo o ano. Circula muita gente aqui, esse é o prazer da gente, que a gente gosta
de lidar com pessoas.

A conviç̧ão da própria capacidade fica evidente na fala da entrevistada 6 , ao afirmar: "Sou capaz de fazer algo diferente para não depender de fumo". Ela ainda afirma que, após o contato com os turistas, o "Bem-estar mudou, é muito bom. Aquele contato com as pessoas, o conhecimento, o bem-estar fica bem melhor. Você tem uma casa bem arrumada, o jardim, mantém o pátio mais em dia".

As entrevistas revelam que a atividade turística desenvolvida por essas mulheres proporciona não só renda e qualidade de vida para o núcleo familiar que reside na propriedade, mas gera possibilidade de renda para a sua extensão, como, por exemplo, cunhadas, filhas, mães, netos, entre outros que residem em outras propriedades ou mesmo na cidade, bem como para membros da comunidade.

A qualidade de vida dessas famílias diz respeito ainda à redução da produção de tabaco, um cultivo que demanda altas doses de veneno e causa sérios problemas de saúde àqueles que as aplicam, bem como ao meio ambiente. Contudo, é importante considerar que o turismo é uma atividade que apresenta entraves e dificuldades; por um lado, por não estar totalmente consolidado nessa região; por outro, por existirem os problemas de infraestrutura que dependem do poder público.

\section{Considerações finais}

Percebemos que, historicamente, as mulheres tiveram seu saber-fazer subestimado ou até mesmo ignorado. Esse processo inclui, entre outras consequências, a invisibilidade, a falta de autonomia, bem como a baixa autoestima das agricultoras familiares.

Embora muito se tenha avançado no que diz respeito às conquistas das mulheres, especialmente no que se refere ao seguimento da agricultura familiar, muitos desafios ainda precisam ser superados, sobretudo ante o avanço do conservadorismo e o 
desmantelamento de canais úteis às agricultoras, como foi o caso da extinção do Ministério do Desenvolvimento Agrário pelo atual governo. Outrossim, mesmo com significativas mudanças em favor das mulheres, percebemos o enraizamento de um pensamento patriarcal, que deslegitima o trabalho feminino e que contribui para manter as mulheres em lugar subalterno.

Ressaltamos que as mulheres são indispensáveis aos processos de manutenção dos saberes populares, dos bancos de sementes crioulas (que atualmente restam ameaçadas pela tramitação no congresso do Projeto de Lei no 827/2015), pela segurança alimentar, entre outros. Nesse sentido, mesmo estando o trabalho feminino, notadamente o que está atrelado ao turismo enquanto aliado na diversificação da renda familiar, relacionado à divisão sexual do trabalho, num modelo que coloca as mulheres em posição inferior à dos homens, temos que o saber-fazer dessas mulheres é fundamental para o desenvolvimento, especialmente para o desenvolvimento da região que analisamos.

As práticas sociais das mulheres do meio rural adquiriram novas roupagens e contribuíram para dar visibilidade às agricultoras familiares, além de empoderá-las e darIhes autonomia. Isso vai ao encontro do desenvolvimento como liberdade, abordado por Sen (2000), já que estamos diante de mulheres de força e de fibra, que conquistaram autonomia, igualdade de autonomia e que lutam diariamente por isso.

Por fim, entendemos que pesquisas que relacionam gênero, espaço rural e desenvolvimento regional são importantes para dar visibilidade a estas mulheres, às agricultoras familiares. O rural e o saber-fazer das mulheres são indispensáveis para o entendimento do mundo, a manutenção das gerações futuras e a segurança alimentar, além da promoção do desenvolvimento regional.

\section{Referências}

ALMEIDA, J. A.; RIEDL, M. Apresentação. In: ALMEIDA, J. A.; FROEHLICH, J. M.; RIEDL, M. Turismo Rural e desenvolvimento sustentável. Santa Maria: UFSM, 1998.

BENI, Mário Carlos. Análise estrutural do turismo. São Paulo: SENAC São Paulo, 2002. 
Política e planejamento de turismo no Brasil. São Paulo: Aleph, 2006.

BENKO, Georges. Economia, espaço e globalização: na aurora do século XXI. Tradução: Antônio de Pádua Danesi. 2. ed. São Paulo: Hucitec, 1999.

BLOS, Wladimir. O turismo rural na transição para um outro modelo de desenvolvimento rural. In: ALMEIDA, J. A.; RIEDL, M. (Orgs.). Turismo rural: ecologia, lazer e desenvolvimento. Bauru: EDUSC, 2000.

BOISIER, Sergio. Em busca do esquivo Desenvolvimento Regional: entre a caixa-preta e o projeto político. Planejamento e Políticas Públicas, n. 13, 1996. Disponível em: <http://189.21.130.9/ppp/index.php/PPP/article/viewFile /135/137>. Acesso em: 10 dez. 2016.

BRANDÃO, C. A. Teorias, estratégias e políticas regionais e urbanas recentes: anotações para uma agenda de desenvolvimento territorializado. Revista Paranaense de Desenvolvimento. Curitiba, n. 107, p. 57-76, jul./dez. 2004.

BRASIL. Lei no 12.512, de 14 de outubro de 2011. Institui o Programa de Apoio à Conservação Ambiental e o Programa de Fomento às Atividades Produtivas Rurais; altera as Leis $\mathrm{n}$-s 10.696, de 2 de julho de 2003, 10.836, de 9 de janeiro de 2004, e 11.326, de 24 de julho de 2006. Disponível em <http://www.mda.gov.br/sitemda/noticias/sancionada-lei-daagricultura-familiar>. Acesso em: 11 jan. 2018.

CRISTÓVÃO, Artur. Mundo rural: entre as representações (dos urbanos) e os benefícios reais (para os rurais). In: RIEDL, Mário; ALMEIDA, Joaquim A.; Viana, Andyara L. B. (Orgs.). Turismo rural: tendências e sustentabilidade. Santa Cruz do Sul: Edunisc, 2002.

GOMES, Antonio Carlos. A operacionalização do mercado institucional de alimentos no contexto do Vale do Rio Pardo: o caso da cooperativa Leoboqueirense de agricultores familiares. 2014. Dissertação (Mestrado em Desenvolvimento Regional) - Universidade de Santa Cruz do Sul, Santa Cruz do Sul, 2014.

GOUVEIA, Raimundo Cândido; ISMAEL, Eliana Costa; CAMINO, Leôncio. Equidade de gêneros e diversidade sexual: propostas para uma sociedade mais justa. In: GENTLE, Ivanilda Matias; ZENAIDE, Maria de Nazaré Tavares; GUIMARÃES, Valéria Maria Gomes. Gênero, diversidade e educação: conceituação e práticas de direito e políticas públicas (Orgs.). João Pessoa: UFPB, 2008.

HERNÁNDEZ, C. O. Política de crédito rural com perspectiva de gênero: um meio de "empoderamento" para as mulheres rurais? 2009 f. 248. Tese (Doutorado em Ciências Econômicas) - Faculdade de Ciências Econômicas. Universidade Federal do Rio Grande do Sul, Porto Alegre, 2009.

PERROT, M. As mulheres ou os silêncios da história. Bauru: EDUSC, 2005 
SCHNEIDER, Sérgio. Agricultura familiar e industrialização: pluriatividade e descentralização industrial no Rio Grande do Sul. Porto Alegre: UFRGS, 1999.

SCOTT, Joan Wallach. Gênero: uma categoria útil de análise histórica. Educação \& Realidade, Porto Alegre, v. 20, n. 2, jul./dez. 1995. p. 71-99.

SEN, Amartya Kumar. Desenvolvimento como liberdade. São Paulo: Companhia das Letras, 2000.

SILVA J. Graziano; CAMPANHOLA, C. O Novo Rural Brasileiro: uma análise nacional e regional. Campinas: EMBRAPA/UNICAMP, 2000. (4 volumes).

SOUZA, Mariana Barbosa de; VERGUTZ, Cristina Luiza Bencke; COSTA, João Paulo Reis. A questão de gênero na Escola Família Agrícola de Santa Cruz do Sul: um olhar sobre o estágio de vivência. Revista Interinstitucional Artes de Educar. Rio de Janeiro, v. 3 n. 1, p. 104-118, mar./jun. 2017. 